\title{
Dinámica poblacional en rebaños que participan en el programa de erradicación de la brucelosis bovina en la Décima Región de Chile ${ }^{\#}$
}

\author{
Population dynamic in herds participating of the bovine brucellosis eradication program \\ in the X Region of Chile \\ C Rosenfeld*1, I de Blas ${ }^{2}$, S Ernst ${ }^{1}$, C Ramírez ${ }^{3}$, A Rivera ${ }^{3}$, E Silva ${ }^{3}$, H Rojas ${ }^{3}$ \\ ${ }^{*} 1$ Instituto de Medicina Preventiva Veterinaria, Facultad de Ciencias Veterinarias, Universidad Austral de Chile, Valdivia, Chile. \\ ${ }^{2}$ Departamento de Patología Animal, Facultad de Veterinaria, Universidad de Zaragoza, España. \\ ${ }^{1}$ Instituto de Medicina Preventiva Veterinaria, Facultad de Ciencias Veterinarias, Universidad Austral de Chile. \\ ${ }^{3}$ Servicio Agrícola y Ganadero, Santiago, Chile.
}

\section{SUMMARY}

\begin{abstract}
The aim of this study was to determine the population risk factors affecting bovine herds in the X Region of Chile in order to obtain a brucellosis free status. A matched case-control study was designed according to the size of the herd and univariate and multivariate statistical tests were applied as well as epidemiological tests. The best results obtained from the control and eradication program were achieved by herds presenting less than $17 \%$ of the initial prevalence levels and in which positive animals were immediately eliminated from the herd.
\end{abstract}

Palabras clave: brucelosis, bovino, dinámica poblacional.

Key words: brucellosis, bovine, population dynamic.

\section{INTRODUCCION}

La brucelosis bovina es una enfermedad infectocontagiosa, zoonósica y ampliamente distribuida en el mundo, causada principalmente por Brucella abortus, y que se caracteriza por abortos al final de la gestación y problemas de infertilidad (Enright 1990). La bacteria penetra en el organismo por vía oral, conjuntival y dérmica, siendo particularmente importantes la ingesta de anexos fecales y pastos contaminados, así como la contaminación de la ubre durante el ordeño. Además se ha comprobado la infección congénita (Blood y col 1988).

Esta enfermedad compromete la competitividad de las producciones al disminuir la eficiencia reproductiva y productiva. Además hay que considerar el riesgo que representa esta enfermedad para la salud pública, por ser una enfermedad zoonósica (Blood y col 1988, SAG 1999).

\section{MEDIDAS DE MEDICINA PREVENTIVA}

FRENTE A LA BRUCELOSIS BOVINA

Crawford y col (1990) indican que diversos factores influyen significativamente en la transmisión de la brucelosis tanto intra como interrebaños, como el nivel de vacunación, el tamaño del rebaño, la densidad

\footnotetext{
Aceptado: 04.07.2006

\# Financiado por Dirección de Investigación y Desarrollo de la Universidad Austral de Chile.

* E-mail: crosenfe@ uach.cl
}

poblacional y el manejo de los partos (sobre todo relacionado con la utilización de maternidades).

Con respecto a la transmisión interrebaños Crawford y col (1990) informan que el mayor factor de riesgo de introducir la enfermedad en un rebaño es a través del reemplazo de animales, por lo que recomiendan realizar un diagnóstico previo de brucelosis antes de efectuar la compra para disminuir dicho riesgo. Otros factores a considerar son la proximidad a rebaños infectados y la presencia de cursos de agua.

En función de la epidemiología de la enfermedad la estrategia técnica aplicada en la erradicación y control de la brucelosis bovina se basa fundamentalmente en la detección de los rebaños infectados, mediante vigilancia epidemiológica, el saneamiento de los rebaños infectados, con el objetivo de eliminar el foco de infección, e impedir la diseminación de la brucelosis, aplicando medidas preventivas para aumentar la inmunidad colectiva (vacunación) y medidas de control (limitación del movimiento de bovinos positivos, establecimiento de cuarentenas, realización de chequeos en ferias y exposiciones ganaderas).

Por tanto, las herramientas claves para poder implementar de forma eficiente esta estrategia de control y erradicación son el diagnóstico y la vacunación.

El diagnóstico de la enfermedad se realiza con pruebas serológicas en serie, utilizando como prueba tamiz el Rosa de Bengala y aplicando a las muestras positivas una batería de pruebas complementarias, que incluyen 
Fijación de Complemento y Rivanol (aunque esta última no está reconocida oficialmente por la OIE) (OIE 1996). Adicionalmente se utilizan las pruebas del Anillo en Leche (Ring-Test), cultivos bacteriológicos (Paredes 1993) y métodos inmunoenzimáticos o ELISA, tanto en suero sanguíneo como en leche (Nielsen y col 1988, 1989, Nielsen 1990, López y col 1998).

El control de la enfermedad se realiza utilizando diversas vacunas ya sea con cepas vivas y muertas, lisas y rugosas. La vacuna viva de la Cepa 19 confiere un poder de protección entre 65 y $75 \%$. Los títulos serológicos son significativos por un período de 10 a 12 meses, y no son posibles de diferenciar de los producidos por la enfermedad (Barton 1994), lo que interfiere en la interpretación de los resultados de las pruebas diagnósticas de rutina para brucelosis al aplicarlas sobre suero y leche (Díaz y col 1968, Cherwonogrodzky y col 1990).

Para eliminar este problema Schurig y col (1991) desarrollaron una vacuna viva con la cepa RB-51 que se caracteriza por carecer de cadena $\mathrm{O}$ como parte de los LPS de superficie, por lo que no genera anticuerpos que afecten a las pruebas diagnósticas convencionales, lo que posibilita que esta vacuna pueda ser aplicada repetidamente, obteniéndose una protección similar a la observada con la vacuna Cepa 19 (Schurig y col 1991).

La vacuna RB-51 se utiliza actualmente en forma oficial en Estados Unidos, en reemplazo de la Cepa 19. Su uso también ha sido aprobado e implementado en Argentina, Colombia, México y Venezuela. Desde julio de 1997 se utiliza en Chile la cepa RB-51 como vacuna oficial frente a Brucella abortus (SAG 1997a).

\section{SITUACION DE LA BRUCELOSIS BOVINA EN CHILE}

La brucelosis bovina es una enfermedad endémica en América Central y Sur, con excepción de Uruguay, Panamá y algunos países del Caribe, y en este contexto, Chile no escapa a la realidad prevalente en Sudamérica (SAG 1997b).

La brucelosis fue descrita serológicamente en Chile en 1930 por médicos veterinarios de la Sociedad Nacional de Agricultura y en 1945 el Ministerio de Agricultura (Paredes 1993) comenzó a preocuparse por esta enfermedad debido a las grandes pérdidas económicas que ocasionaba en la ganadería nacional.

En el año 1975 se realizó el primer estudio para determinar la situación de la enfermedad en el territorio nacional, en el que se detectó una prevalencia de un 20,4\% en los rebaños y un $7 \%$ en los animales. En ese mismo año la División de Protección Pecuaria del Servicio Agrícola y Ganadero decidió poner en marcha un proyecto orientado a controlar la enfermedad en una primera etapa, para luego abordar su eventual erradicación. El proyecto (Amthauer y col 1993, Paredes 1993) contemplaba básicamente el uso de la vacunación con Cepa 19, a las terneras entre los 3 y 8 meses de edad, como única herramienta de control de la enfermedad. Esta actividad se realizó entre las regiones IV a X.

En 1982 esta estrategia había conseguido la disminución de la prevalencia nacional de brucelosis bovina al $2,9 \%$ del censo de bovinos. Con estos resultados la División de Protección Pecuaria, viendo la necesidad de consolidar la situación sanitaria lograda (caracterizada por unos niveles bajos de infección predial) y al mismo tiempo poder mejorar la comercialización de bovinos de reproducción, tanto a nivel nacional como internacional, incorporó como nueva línea de acción la Certificación de Predios (Rebaños) Libres de brucelosis bovina, que se inició en la X Región del país. La estrategia de esta nueva línea de acción consistió en mantener la vacunación de terneras de reposición complementándose con la realización de chequeos periódicos y el envío de animales positivos a matadero sin indemnización por parte del Estado. La incorporación de los rebaños a este programa de Certificación estaba condicionada a un ingreso voluntario y a que el ganado reuniera características genéticas y productivas compatibles con los objetivos planteados. Al mismo tiempo, debían tener condiciones epidemiológicas y de manejo que permitieran mantener un estado sanitario óptimo a través del tiempo (Paredes 1993).

Debido a una escasa disminución de la prevalencia de brucelosis bovina se optó por definir un nuevo proyecto que aplicaría estrategias para lograr la erradicación de la brucelosis entre la IV y X regiones, que se configuró como el Programa de Erradicación de Brucelosis Bovina a nivel nacional (SAG 1995a).

Este proyecto de erradicación se implementó progresivamente en 1991 iniciándose en la XII Región, en 1993 en la XI, en 1995 en las provincias de Chiloé y Palena, en 1996 en las provincias de Valdivia, Osorno y Llanquihue de la X Región, y en 1997 las regiones de IX y al norte (SAG 1977b). Esta estrategia plantea desde el punto de vista técnico un enfoque predial, ya que considera que la brucelosis bovina es una enfermedad comunitaria, y por tanto debe ser abordada de acuerdo a la situación y características del área afectada. Por esta razón la intensidad de algunas acciones varía según el área afectada y a la presentación de la enfermedad. Además, considera la participación del sector privado, existiendo varias actividades que deberán ser ejecutadas por médicos veterinarios acreditados (SAG 1995a).

En Chile, la brucelosis bovina está concentrada en la X Región del país. En un estudio de prevalencia en 1991 se determinaron tasas de animales seropositivos que fluctuaron entre un 23 y un $38 \%$ según la provincia, además información obtenida en el año 1997 revela que más del $60 \%$ de los rebaños infectados del país se localizan en esta región (SAG 1997a) afectando con mayor frecuencia a rebaños de orientación lechera (SAG 1997b).

La política sanitaria en Chile para erradicar la brucelosis se basa en tres fundamentos (SAG 1997b): 
1. Localización de rebaños infectados: a través de la detección de nuevos rebaños infectados realizando diagnósticos en plantas lecheras, centros de acopio, queserías y centros de recolección, mataderos, ferias de ganado, remates en predios y exposiciones, muestreo de rebaños adyacentes y contactos, muestreo de áreas y atención de denuncias.

2. Saneamiento de los rebaños infectados: es decir, eliminar la infección por $B$. abortus en un rebaño mediante el ataque directo de la fuente de infección (para cortar la transmisión intrarrebaño) a través de cuatro líneas de actuación principales: establecimiento de un plan de manejo de rebaño infectado, consecución de inmunidad colectiva mediante vacunación, realización de muestreos seriados del rebaño y eliminación de animales reaccionantes (positivos).

3. Impedir la diseminación de Brucella abortus: el objetivo es la reducción de la exposición de los rebaños a fuentes de infección mediante la vacunación de terneras y de rebaños de riesgo, el control del movimiento de bovinos infectados y expuestos, el establecimiento de cuarentenas de rebaños infectados, el control de ferias de ganado, remates prediales, exposiciones ganaderas, la obtención de certificación sanitaria de venta de bovinos de reproducción y la declaración de áreas libres.

Se destaca que en 1997 se incorporó la vacuna cepa RB-51 de forma oficial en todo Chile, reemplazando la vacuna Cepa 19 que fue la vacuna que acompañó el proceso de control por 20 años (SAG 1997a, 2004).

Con respecto al avance del control de la enfermedad, entre los años 1976 y 1982 se observó una disminución de la prevalencia de un $7 \%$ a $2,9 \%$, por lo que en seis años se alcanzó la meta propuesta para una década de programa. Sin embargo, en los nueve años siguientes (1982-1991) prácticamente no se apreció una disminución significativa de ésta (SAG 2005).

De acuerdo con todo lo anteriormente expuesto establecimos como objetivo la realización de un estudio epidemiológico de los rebaños en el proceso de saneamiento, que permita determinar factores de riesgo asociados con la dinámica poblacional así como con el manejo de los rebaños, tanto para lograr la eliminación de animales positivos como su mantenimiento como rebaños saneados.

\section{MATERIAL Y METODOS}

Origen de los datos. Para el estudio se extrajo la información de las bases de datos del Servicio Agrícola y Ganadero (SAG) que contienen los registros de los rebaños bovinos que participan en el Programa de Erradicación de Brucelosis Bovina. Los rebaños se localizaron en la provincia de Valdivia (39 $48^{\circ}$ S; $73^{\circ} 14^{\prime}$ 'W) en la $\mathrm{X}$ Región, en el sur de Chile. El periodo de estudio se inició desde 1996; sin embargo, existe un periodo interno para cada rebaño que corresponde a los días entre el primer y el último control.

Se trabajó sobre la información disponible de todos los rebaños pertenecientes a la oficina de Paillaco del SAG que al ingresar en el programa se encontraban serológicamente positivos a brucelosis bovina, lo que supuso un total de 410 rebaños. Se estudió su evolución en el tiempo desde cuando se realizó una primera clasificación en la que se determinó su situación de saneamiento, definiéndose como rebaño saneado a aquel que presentó al menos tres chequeos serológicos consecutivos negativos y como rebaño en saneamiento al que presentó al menos un animal reaccionante en los chequeos serológicos realizados.

Posteriormente se seleccionaron todos los rebaños saneados y se procedió a ordenarlos en función del número de animales presentes en el primer control. A continuación se realizó un pareamiento por tamaño con rebaños en proceso de saneamiento, buscando las mínimas diferencias de tamaño entre los rebaños del estudio (el tamaño del rebaño caso es similar que el rebaño control). La muestra quedó constituida finalmente por 82 rebaños: 41 en proceso de saneamiento definidos como casos y 41 saneados como rebaños controles (cuadro 1).

Una vez seleccionados los rebaños se procedió a extraer la información de las bases de datos que contenían toda la información disponible de los movimientos de animales (González 1999) que se encontraban en formato Microsoft Excel, y que contenían los registros de los controles realizados tales como fecha del control, total de animales muestreados, total de animales positivos, tipo de producción y sistema de reposición. Así como de la base de datos de animales que contenía la información de cada uno de los animales pertenecientes a los distintos rebaños seleccionados, y a los que se le habían realizado controles serológicos.

Métodos serológicos. Los criterios que se utilizaron para el diagnóstico serológico en los rebaños que participan en el Programa de Erradicación de Brucelosis Bovina se basaron en la toma de muestras a todas las hembras ma-

Cuadro 1. Tamaño y condición de los rebañoss seleccionados en el estudio.

Size and condition of the herds selected in the study.

\begin{tabular}{lccrrrr}
\hline \multirow{2}{*}{$\begin{array}{l}\text { Número de } \\
\text { Animales }\end{array}$} & \multicolumn{2}{c}{ Condición de los Rebaños } & & \multicolumn{2}{c}{ Total } \\
\cline { 2 - 3 } \cline { 6 - 7 } \cline { 6 - 7 } & En saneamiento & Saneados & & $\mathrm{N}^{\circ}$ & $\%$ \\
\hline 50 & 31 & 31 & & 62 & 75,6 \\
$50-200$ & 7 & 7 & & 14 & 17,1 \\
$>200$ & 3 & 3 & & 6 & 7,3 \\
Total & 41 & 41 & & 82 & 100 \\
\hline
\end{tabular}


yores de 18 meses y a los machos reproductores pertenecientes a rebaños positivos a la prueba del Anillo en Leche a los que se les practicó en serie la prueba de Rosa de Bengala en primer lugar y a las muestras que resultaron positivas se les efectuó la Fijación de Complemento, buscando reducir los falsos positivos y por tanto aumentar la especificidad. Todas las pruebas fueron realizadas según protocolos internacionales (OIE, 1996). Al confirmarse la seropositividad de algún individuo por Fijación de Complemento, considerando positivo cualquier título igual o superior a 1: 10 (SAG, 1995b, 2004), el rebaño al que pertenece se clasifica como infectado de brucelosis bovina y se procede a su inclusión en el programa de control y erradicación.

Variables estudiadas. Se estudiaron las variables que caracterizaban el comportamiento de los rebaños participantes en el programa, así como otras que permitieran estudiar la dinámica poblacional:

a) Caracterización del comportamiento de los rebaños en el programa:

- Periodo de permanencia en el programa (días).

- Número de chequeos realizados: en el estudio participaron rebaños a los que como mínimo se les realizó 3 chequeos serológicos. Con esta condición todos los rebaños seleccionados tuvieron la posibilidad de lograr la condición de rebaño saneado, desde su ingreso al programa.

- Porcentaje del periodo de permanencia con animales negativos: considerando que los chequeos no se hacen a intervalos iguales, se establece el tiempo que el rebaño se mantiene negativo con respecto al tiempo total que el rebaño ha permanecido en el programa (es decir, desde el primer chequeo completo hasta el último chequeo completo).

- Número de rebaños que pierden el estatus negativo durante el estudio: este índice se incluyó debido a la constatación del hecho de que en ocasiones los rebaños han logrado obtener chequeos negativos pero han sido incapaces de mantener dicha condición a lo largo del tiempo.

- Porcentaje de animales que ingresan en los rebaños.

b) Dinámica poblacional de los rebaños:

- Ingreso de animales nuevos en el rebaño y porcentaje medio de reposición externa: debido a que en los chequeos realizados en los rebaños del estudio se observó la existencia de nuevos animales, se determinó este porcentaje como la media de los porcentajes de animales introducidos, y no chequeados en ningún muestreo anterior, en cada chequeo con respecto al total de animales de dicho chequeo. Esta variable determina el impacto del grado de reposición (introduc- ción de animales) en el rebaño sobre el programa de control y erradicación.

- Ingreso de nuevos animales positivos en el rebaño: permite cuantificar el grado de cumplimiento de las medidas de control de movimiento de animales positivos, del correcto establecimiento de cuarentenas y de chequeos serológicos de los animales introducidos en el rebaño y producto de la autorreposición. Debido a la construcción de la base de datos no se pudo establecer si estos nuevos animales positivos son a causa de reposición interna o si es externa.

- Sistema de reposición: se diferenció entre los rebaños en los que se practicaba una reposición exclusivamente interna (autorreposición) y los que introducían animales adquiridos directamente en otros rebaños y/o en ferias ganaderas.

c) Dinámica de la enfermedad en los rebaños:

- Prevalencia inicial de brucelosis bovina de los rebaños obtenida en el primer chequeo completo.

- Presencia de animales positivos no eliminados en el rebaño: a través de esta variable se puede estimar el correcto cumplimiento de las medidas orientadas a la oportuna eliminación de animales positivos dentro de un rebaño tras la realización de un chequeo.

- Determinación de animales que seroconvirtieron positivamente con respecto al chequeo anterior.

d) Características de los rebaños

- Tipo de explotación según la aptitud de los animales: se clasificaron en carne y mixto-leche.

Para el análisis de las variables se calcularon en primer lugar los estadísticos descriptivos tanto para variables cuantitativas y cualitativas. A continuación se procedió a determinar la existencia de asociación estadística entre variables cuantitativas, utilizando el contraste t de Student para muestras independientes o la prueba de KruskalWallis (para un nivel de significación de $\mathrm{P}$ 0,05) en función de la homocedasticidad de las variables estudiadas, mientras que para las variables cualitativas se determinaron los Odds Ratios (OR) con sus correspondientes intervalos de confianza (IC 95\%). En un primer análisis univariante, se estimaron los efectos crudos y ajustados para las principales variables de interés (Rothman 1987). Posteriormente, mediante el procedimiento de regresión logística condicional, se realizó un análisis multivariante. En el modelo final multivariante se incluyen aquellas variables cuyo efecto es estadísticamente significativo e independiente del efecto de las demás variables (Egret 1999).

Se utilizaron los programas computacionales Win Episcope 2.0 (Thrusfield 2001) y Egret 2.0.3 para Windows (Egret 1999) para el tratamiento y análisis de la información. 


\section{RESULTADOS}

El comportamiento de los rebaños en saneamiento indicó que estos rebaños permanecen en el programa sin sanearse más tiempo que los rebaños saneados, esta situación también se reflejó en el número de pruebas realizadas siendo 6,4 pruebas frente a las 4,2 pruebas que se realizan en los que se sanean. Aunque en promedio los rebaños en saneamiento lograron tener pruebas sin animales positivos durante el $25 \%$ del periodo en que están en el programa, prácticamente la mitad (20 rebaños de 41) perdieron la condición de negatividad. La pérdida del estatus negativo también se produjo en los rebaños que lograron sanearse, pero esto sólo ocurrió en 7 rebaños. En cuanto al estudio de ingreso de animales no se determinaron diferencias significativas en la aparición de nuevos animales en los chequeos, ésta osciló entre 31\% y $28 \%$ en cada grupo respectivamente (cuadro 2). Con respecto a este tema en la base de datos no se pudo identificar si el origen de estos nuevos animales era por reposición externa o interna (procedentes del propio predio).

Al estudiar la situación sanitaria inicial de los grupos estudiados se observó que a partir de una prevalencia superior al $17 \%$ fue cuando se producía el mayor riesgo de no alcanzar la condición de rebaño saneado. Al estudiar el tipo de explotación u orientación de la producción no se determinó que esta variable se comportara como factor de riesgo.

A pesar de que, tanto en rebaños en saneamiento como en los saneados, el ingreso de animales en los chequeos fue de un 30\% aproximadamente (cuadro 3), se observó una clara diferenciación, y se apreció que en los rebaños en saneamiento en el 83\% de éstos ingresaron animales positivos en relación al 24\% de los rebaños que lograron sanearse, determinándose como que esta circunstancia actuaba como factor de riesgo (cuadro 3 ).

Cuadro 2. Descripción del comportamiento de los rebaños en el programa.

Description of the behavior of the herds in the program.

\begin{tabular}{lcccc}
\hline & \multicolumn{2}{c}{ Condición de los rebaños } & \\
\cline { 2 - 3 } Variable & En saneamiento & Saneados & \\
\cline { 2 - 3 } & Media \pm DE & Media \pm DE & $P$ \\
\hline $\begin{array}{l}\text { Periodo de permanencia } \\
\text { en el programa (días) }\end{array}$ & $1050 \pm 336,5$ & $677 \pm 355,0$ & 0,000 \\
$\begin{array}{l}\text { Número de chequeos realizados } \\
\text { \% del periodo de permanencia }\end{array}$ & $6,4 \pm 2,2$ & $4,2 \pm 0,97$ & 0,000 \\
en rebaños con animales negativos & $25,0 \pm 25,6$ & $72,4 \pm 27,9$ & 0,000 \\
$\begin{array}{l}\text { No de rebaños que pierden el estatus } \\
\text { negativo durante el estudio }\end{array}$ & $20 / 41$ & $7 / 41$ & \\
$\begin{array}{l}\text { Porcentaje de animales que ingresan } \\
\text { en los rebaños }\end{array}$ & $31,1 \pm 12,8$ & $28,0 \pm 17,6$ & 0,36 \\
\hline
\end{tabular}

* DE: Desviación Estándar.
Otra variable estudiada fue la permanencia de animales positivos en el rebaño, ya que en el $82.9 \%$ de los rebaños en saneamiento no se eliminaban los animales una vez diagnosticados como positivos, y aunque esta situación también se presentó en un 41,4\% de los rebaños saneados, en el análisis univariante se determinó que esta variable se comportaba como factor de riesgo.

Finalmente se realizó un análisis multivariante creando un modelo de regresión logística (cuadro 4) con las variables que habían mostrado asociación significativa en el estudio univariante. Se determinó que tanto una prevalencia inicial superior a un $17 \%$ así como la permanencia de animales positivos eran los únicos factores de riesgo que afectaban negativamente a la probabilidad de que los rebaños estudiados lograran sanearse.

\section{DISCUSION}

En el estudio se observó una clara diferenciación de comportamiento de los rebaños en el programa tanto en el tiempo de permanencia, número de pruebas, tiempo de permanencia sin animales positivos y pérdida de la condición de negatividad. Para buscar el origen de estas diferencias de comportamiento, según la condición de

Cuadro 3. Prevalencias y variables poblacionales de los rebaños en estudio.

Prevalence and population variables of the herds in the study.

\begin{tabular}{lccc}
\hline \multirow{2}{*}{ Variables } & \multicolumn{3}{c}{ Condición de los rebaños } \\
\cline { 2 - 4 } & En saneamiento & Saneados & OR (IC 95\%) \\
\hline Prevalencia inicial >17\% & $41 \%$ & $7,3 \%$ & $8,27 *(2,20-51,43)$ \\
\hline Tipo de explotación & & & \\
$\quad$ Carne & $7,3 \%$ & $2,4 \%$ & $1,5(0,12-40,3)$ \\
$\quad$ Leche & $41,5 \%$ & $53,7 \%$ & $0,61(0,23-1,60)$ \\
$\quad$ Mixta (leche y carne) & $51,2 \%$ & $43,9 \%$ & $1.34(0,51-3,54)$ \\
$\begin{array}{l}\text { Ingreso de animales } \\
\text { positivos }\end{array}$ & & & \\
$\begin{array}{l}\text { Origen de animales } \\
\text { de reposición }\end{array}$ & $33 \%$ & $24 \%$ & $15,06^{*}(4,56-52,42)$ \\
Permanencia de positivos & & & \\
en los chequeos & $82,9 \%$ & $34,1 \%$ & $11,25^{*}(3,43-38,82)$ \\
Presencia de animales & & & \\
que seropositivizan & $92,6 \%$ & $41,4 \%$ & $17,88^{*}(4,26-101,17)$ \\
\hline
\end{tabular}

* OR significativo para un nivel de confianza del $95 \%$.

Cuadro 4. Modelo final de regresión logística. Final model of logistic regression.

\begin{tabular}{lrrrrr}
\hline Variable & Coef. & Error DE & P & OR & IC 95\% \\
\hline $\begin{array}{l}\text { Permanencia } \\
\text { de animales positivos }\end{array}$ & 3,08 & 1,16 & 0,008 & 21,90 & $(2,23-214,4)$ \\
Prevalencia inicial $>17 \%$ & 2,7 & 1,32 & 0,04 & 14,89 & $(1,11-201,70)$ \\
\hline
\end{tabular}


saneamiento en el Programa de Erradicación de la Brucelosis Bovina, se estudiaron la condición inicial de la enfermedad en los rebaños y variables poblacionales, utilizando la clasificación propuesta por Salman y Meyer (1984), en donde estudia la causalidad de la iniciación, mantenimiento, difusión y control o erradicación de la brucelosis bovina en tres categorías de acuerdo a las características de la población animal, el estilo de manejo y las características biológicas de la enfermedad.

Dentro de las características de la población animal la condición inicial en cuanto al nivel de animales positivos es un factor fundamental ya que se determinó, tanto en el análisis epidemiológico univariante como en el análisis de regresión logística, que cuando la prevalencia de partida es superior al $17 \%$ se produjeron mayores dificultades para lograr el saneamiento de los rebaños. Esta situación concuerda con otros estudios que indican que al existir una alta proporción de animales infectados con la enfermedad, ésta es más persistente y se producen mayores dificultades para su erradicación (Salman y Meyer 1984). Además, se debe indicar que a los productores que participan en el programa no se les indemnizaba por los animales positivos eliminados, por lo que para los dueños de los rebaños afectados con prevalencias altas significaba aumentar la tasa de reposición y por tanto un encarecimiento de los costes de producción. Una forma de incentivar el saneamiento sería mediante un pago diferencial por parte de la industria lechera a los rebaños que se encuentren libres de brucelosis (Samartino 2002).

En el sistema de producción chileno, además de la producción de leche y carne, se realiza un tipo de producción mixta en que un mismo rebaño se orienta tanto para la producción lechera como cárnica, debido principalmente a las condiciones del mercado. Si se considera que en este estudio predominaron las explotaciones mixtas y de leche, no existiendo en ellas una marcada diferencia de manejo ya que en ambas se produce leche y de que sólo se incluyeron en el estudio 4 rebaños dedicados en exclusiva a la producción cárnica, no se pudieron determinar diferencias significativas al considerar la influencia de este factor. Sin embargo, en otro estudio realizado se determinó que el tipo de explotación era un factor de riesgo (Kellar y col 1976).

Dentro de las medidas de manejo de los rebaños propiamente dichas se encuentran el origen y condición de los animales de reposición o reemplazo en los rebaños. Se estima que el movimiento de animales de reemplazo por sí solo no contribuye a la diseminación de la enfermedad en los rebaños (Amthauer y col 1993, Salman y Meyer, 1984), a no ser que se introduzcan animales infectados, considerándose este factor como uno de los principales en la introducción de la enfermedad en rebaños no infectados (Gil Turnes y col 1975, Goyon 1971, Kellar y col 1976).

En el presente estudio se determinó que en ambos grupos la tasa de reposición fue cercana al 30\%, pero al estudiar la condición sanitaria de los animales introducidos se observó el ingreso de animales positivos en los rebaños. En el caso de los rebaños que realizan reposición interna (autorreposición), y donde se obtuvieron resultados diagnósticos positivos para estos nuevos animales, podemos concluir que estos animales se contagiaron a partir de animales positivos previamente existentes, ya que todos los rebaños en el estudio presentaban como mínimo un animal reaccionante a las pruebas serológicas en el momento de su ingreso al programa. Sin embargo, la mayor reactividad detectada en el caso de rebaños que practicaban reposición externa podría deberse a la compra de animales de reposición procedentes de rebaños no saneados, sin adoptar las mínimas precauciones con respecto a la realización de pruebas serológicas antes de ingresarlos al rebaño.

Por otro lado queda en evidencia que no se cumple la exigencia del programa que indica que los animales serológicamente positivos deberían ser eliminados por sacrificio en matadero, y ello implica una redistribución de animales positivos en los rebaños y un aumento de la recirculación de la bacteria dentro de los rebaños. Aunque frente a la pregunta del origen de los animales de reposición en ambos grupos señalamos que en este estudio fue predominantemente interna y no pudo establecerse su comportamiento como factor de riesgo.

Otra variable que demostró su gran influencia en el modelo de regresión logística fue la permanencia en los rebaños de animales positivos. Esta situación permite mantener el ciclo de la enfermedad, y aunque esta situación se presentó en ambos grupos, en los rebaños que lograron sanearse el tiempo de permanencia fue menor. En el presente estudio se ha visto que a través del diagnóstico y remoción de los animales reactores se puede reducir en forma significativa la diseminación de la enfermedad dentro del rebaño.

Tanto el ingreso de animales positivos como la deficiente eliminación de animales positivos indicaron que los productores que gestionaban los rebaños que no lograron sanearse no ejercen con disciplina el programa propuesto para el control del rebaño infectado y se limitaron tan sólo a las pruebas, similar situación se ha encontrado en otros estudios (Amthauer y col 1993, Rentería y col 2003, Salman y Meyer, 1984).

La aparición de animales que inicialmente eran negativos y en exámenes serológicos posteriores aparecen como positivos, se podría explicar teniendo en cuenta la circunstancia de que antes de junio de 1997 los rebaños eran vacunados con Cepa 19. En un estudio comparativo de las vacunas RB-51 y Cepa 19 en la zona sur de Chile se observó que la vacunación con Cepa 19 producía animales seropositivos, mientras que la vacunación con RB-51 no mostraba seropositividad por la técnica diagnóstica utilizada (Ramírez y col 2002), lo que coincide con otro estudio (Olsen y col 1996). Además, también se han descrito reacciones de falsos positivos relacionados con reaccio- 
nes cruzadas con infecciones por Yersinia enterocolitica O: 9 y otros agentes sin identificar (Pouillot y col 1998). La existencia de estas reacciones cruzadas y la persistencia de títulos dificultaría la clasificación de los animales infectados, ya que existen animales sanos que seroconvierten y se clasifican como positivos y se debería esperar a muestreos posteriores antes de poder ser clasificados definitivamente como animales positivos o negativos a brucelosis (Nicoletti 1990), lo que implica un mayor tiempo de saneamiento, y se recuerda que en este estudio se ha determinado que esta variable es un factor de riesgo.

En consideración a los resultados se puede concluir que en la situación sanitaria y productiva de los rebaños bovinos en Chile, los dos factores fundamentales que afectan al éxito del programa de control y erradicación de la brucelosis bovina fueron la permanencia en el rebaño de animales positivos (fracaso de la estrategia de sacrificio inmediato de animales reaccionantes) y las prevalencias de infección superiores al 17\% (que podría marcarse como umbral para decidir si aplicar una estrategia de control o erradicación en el rebaño).

Así pues, cuando los recursos económicos sean limitados y no sea posible indemnizar el sacrificio de los animales sospechosos, y se desee mejorar o diseñar futuros planes de erradicación en poblaciones, se deberá buscar el punto de equilibrio entre los factores económicos y el aumento de riesgo derivado del incremento de la permanencia de dichos animales sospechosos en el rebaño

\section{RESUMEN}

El objetivo del presente estudio es determinar los factores de riesgo poblacionales que afectan a los rebaños bovinos de la X Región de Chile para obtener la condición de predio libre de brucelosis. Se diseñó un estudio de casos y controles pareado de acuerdo al tamaño del rebaño, realizándose análisis estadísticos univariados y multivariados, así como test epidemiológicos. Los mejores resultados en el programa de control y erradicación se logran con rebaños que presentan una prevalencia inicial menor al $17 \%$ y que eliminan inmediatamente los animales positivos.

\section{REFERENCIAS}

Amthauer E, A Rivera, L Paredes, H Galleguillos, O Muñoz, B Pérez, J Soto. 1993. Saneamiento y certificación de predios libres de brucelosis bovina. Proyecto de Saneamiento y certificación de predios libres de brucelosis, tuberculosis y leucosis bovina. Informe final 1988-1992. Ministerio de Agricultura, Servicio Agrícola y Ganadero, Chile, Pp 19-25.

Barton C. 1994. Brucellosis Training Course. Servicio Agrícola y Ganadero, Chile, Pp 113.

Blood DC, J Henderson, O Radostist. 1988. Medicina Veterinaria ( $7^{\mathrm{a}}$ ed). Nueva Editorial Interamericana. Londres, Pp 729-742.

Cherwonogrodzky JW, G Dubray, E Moreno. 1990. Antigens of Brucella. In: Nielsen K, Duncan JR (Eds.). Animal Brucellosis. Boca Ratón, Florida CRC Press, USA, Pp 19-64.

SAG, Servicio Agrícola y Ganadero, Chile. 1995a. Estrategia Técnica para la Erradicación de la Brucelosis Bovina. Informe.

SAG, Servicio Agrícola y Ganadero, Chile. 1995b. Saneamiento de rebaños infectados con Brucelosis Bovina utilizando vacunación de hembras adultas con Cepa 19 en dosis diluida. Informe.
SAG, Servicio Agrícola y Ganadero, Chile. 1997a. Informe Anual Proyecto Erradicación de Brucelosis Bovina, X Región. Informe.

SAG, Servicio Agrícola y Ganadero, Chile 1997b. Proyecto Apoyo al saneamiento y vigilancia para la Erradicación de Brucelosis Bovina, en los pequeños ganaderos de las Provincias de Valdivia, Osorno y Llanquihue. Informe.

SAG, Servicio Agrícola y Ganadero, Chile. 1999. Erradicación de Brucelosis Bovina X Región. Informe.

SAG, Servicio Agrícola y Ganadero, Chile. 2004. Programa Oficial de Erradicación de Brucelosis Bovina PEBB/MP1 Anexo $\mathrm{N}^{\circ} 2$ Procedimientos de Erradicación de Brucelosis Bovina.

SAG, Servicio Agrícola y Ganadero, Chile. 2005. Boletín Veterinario Oficial. Salud Animal e Inocuidad de Alimentos. División de Protección Pecuaria.

Crawford RP, JD Huber, BS Adams. 1990. Epidemiology and surveillance. En: K. Nielsen and J.R. Duncan (eds.). Animal brucellosis. CRC Press Inc., Boca Raton, Florida, USA, Pp 131-151.

Díaz R, LM Jones, D Leons. 1968. Surface antigens of smooth brucellae. J Bacteriol 96, 893-901.

Egret 2.0.3. 1999. Statistics and Epidemiology. Research Corporation, Seattle, WA.

Enright FM. 1990. The pathogenesis and pathobiology of Brucella infection in domestic animals. En: Nielsen K, Duncan JR (Eds). Animal Brucellosis. Boca Raton, Florida CRC Press. USA, Pp 01320.

Gil Turnes C, JA Giraudo, A Ambrogi. 1975. Comparison of the prevalence of bovine brucellosis in open and closed herds. Zoonosis 18: 192-195.

González L. 1999. Evaluación y análisis de la Ficha Epidemiológica Predial utilizada por el Servicio Agrícola y Ganadero en el Proyecto de Erradicación de Brucelosis Bovina. Tesis MV, Universidad Austral de Chile, Facultad de Ciencias Veterinarias, Valdivia, Chile.

Goyon P. 1971. Consequences pour la prophylaxie de la brucellose bovina des donnes epidemiologiques, bacterologiques et serologiques. Recl Med Vet 147: 837-845.

Kellar J, R Marra, W Martin. 1976. Brucellosis in Ontario: A case control study. Can J Comp Med 40: 119-128.

López J, A Best, C Morales. 1998. Diagnóstico de brucelosis bovina en leche por el Ring Test y ELISA en lecherías de la provincia de Nuble (VIII Región). Arch Med Vet 30, 133-138.

Nicoletti P. 1990. Vaccination. En: Nielsen K, Duncan JR (eds.). Animal Brucellosis. Boca Raton, Florida CRC Press, USA, Pp 83-299.

Nielsen K, PF Wright, WA Kelly, JW Cherwonogrodzky. 1988. A review of enzyme immunoassay for detection of antibody to Brucella abortus in cattle, Vet. Immunol. Immunopathol. 24: 373382.

Nielsen, KH, JW Cherwonogrodzky, JR Duncan, DR Bundle. 1989. Enzyme-linked immunosorbent assay of differentiation of the antibody of cattle naturally infected with Brucella abortus or vaccinated with Strain 19. Am J Vet Res 50, 5-9.

Nielsen K. 1990. The serological response of cattle immunized with Yersinia Enterolitica 0: 9 or to Yersinia and Brucella abortus antigens in enzyme immunoassay. Vet Immunol Immunopathol 24, 373-382.

Olsen SC, D Evans, SG Hennager, NF Cheville, MG Stevens. 1996. Serologic responses of Brucella abortus strain 19 calfhoodvaccinated cattle following adult vaccinationwith strain RB-51. $J$ Vet Diagn Invest 8, 451-454.

Organización Internacional de Epizootias (OIE). 1996. Manual of Standards for Diagnostic Test and Vaccines. 3th ed. OIE, París, France, Pp 242-250.

Paredes L. 1993. Experiencias en control de brucelosis bovina. Primeras Jornadas Chilenas de Buatría, Osorno, Chile, Pp 67-77.

Pouillot R, PH Lescoat, B Garin-Bastuji B, D Repiquet, P Terrier, G Gerbier, JJ Bénet, M Sanaa. 1998. Risk factors for false-positive 
serological reactions for bovine brucellosis in Saône-et-Loire (France). Prev Vet Med 35, 165-179.

Ramírez M, S Ernst, F Elvinger, A Rivera, C Rosenfeld. 2002. Respuesta serológica y tiempo de saneamiento en rebaños bovinos con brucelosis vacunados con Cepa 19 o Cepa RB51; X Región, Chile. Arch Med Vet 34 (2).

Rentería T, K Nielsen, A Fedorovish, M Montaño, J Moreno. 2003. Evaluación de un programa de control de la brucelosis bovina en hatos lecheros de Baja California. Téc Pecu Méx 41, 275-282.

Rothman K. 1987. Epidemiología Moderna. Ediciones Díaz de Santos, S.A.
Salman M, M Meyer. 1984. Epidemiology of bovine brucellosis in the Mexicali Valley, Mexico: Literature review of diseaseassociated factors. Am. J. Vet. Res. 45; 1557-1559.

Samartino L. 2002. Brucellosis in Argentina. Vet Microbiol 90, 71-80.

Schurig GG, RM Roop, T Bagchi. 1991. Biological properties of RB51: A stable rough strain of Brucella abortus. Vet Microbiol 28, 171-188.

Thrusfield M, C Ortega, I de Blas, JP Noordhuizen, K Frankena. 2001. Win Episcope 2.0: improved epidemiological software for veterinary medicine. Vet Rec 148, 567-572. 